\title{
Evaluation of three preparation methods for living diatoms at a sandy river- mouth tidal flat: conventional acid-cleaning, nuclear staining, and sieving
}

\author{
Mariko YAMAмото $^{1 *} \&$ Taisuke OHTSUKA ${ }^{2}$ \\ ${ }^{1}$ Graduate School of Environmental Studies, Nagoya University, Furo-cho, Chikusa, Nagoya, Aichi, 464-8601, \\ Japan; *Corresponding author e-mail: yamamoto.mariko@h.mbox.nagoya-u.ac.jp \\ ${ }^{2}$ Lake Biwa Museum, 1091 Oroshimo-cho, Kusatsu, Shiga, 525-0001, Japan
}

\begin{abstract}
Three preparation methods for the identification of diatom flora at a river mouth tidal flat were evaluated in terms of species richness, diversity, and composition using a conventional acid-cleaning method, a nuclear staining method, and a newly introduced sieving method. Twenty-five diatom samples were collected from Fujimae Tidal Flat sediments, Nagoya, Japan, in July 2014. Three methods respectively showed different aspects of the diatom flora. The acid-cleaning method indicated the highest species diversity, but it extracted dead diatoms with living ones indiscriminately. In comparison with the acid-cleaning method, the staining method effectively extracted diatoms with fragile and small-sized cells. The sieving method scraped the sessile diatoms selectively and supplemented the staining method in which sessile diatoms were mostly neglected. A combination of these three methods enables to describe precise diatom flora of a tidal flat.
\end{abstract}

Key words: diatom flora, Hematoxylin, nuclear staining method, river mouth tidal flat, sieving method

\section{INTRODUCTION}

Benthic diatoms often become dominant at the sedimentwater interface where biogeochemical cycles are highly active. They play an important role in the food web as primary producers, especially in sandy and muddy sediments without vegetation (SMITH \& UNDERWOOD 1998; UNDERWOOD \& KROMKAMP 1999). Tidal flats are one such habitat where benthic diatoms are usually dominant. Evaluating diatom species composition is therefore very important for understanding the tidal flat ecosystem.

Our understanding of diatom flora at river mouth tidal flats is complicated by allochthonous diatoms. These diatoms are transported by river or tidal flows and are usually found as dead frustules or valves without cytoplasm (Kosugi 1986a, b; SAWAi 2001; ChiBA et al. 2011). We cannot separate these dead diatoms from living ones with conventional preparation methods, which include the chemical cleaning of frustules or valves (Gотон 1988; KosUGI 1988; SAWAI 2001). Valve cleaning is necessary for precise identification of species based on their fine structures; therefore, alternative observation techniques must be combined as described below.

Nuclear staining methods are useful in distinguishing living cells from dead ones. Among these methods, DNA-specific fluorochrome 4',6-diamidino-2-phenylindole (DAPI) staining is well known in cell biology.
However, it is not suitable for the evaluation of living diatoms because the simultaneous observation of nuclear fluorescence and the fine structures of valves is impossible. Other staining methods such as Acetocarmine staining (MAYAMA \& KobayAsI 1982), Hematoxylin and Eosin staining (Kosugi 1985), and Hematoxylin staining (Gотон 1988) enable the observation of fine valve structures and therefore are suitable for both living and dead diatoms. Of these methods, the simplest and most practical is the Hematoxylin staining method developed by Gотон (1988).

Unfortunately, these staining methods cannot detect most epipsammic diatoms firmly attached to sand grains, because these methods do not decompose the mucilage by which diatoms attach to the substrata. This may lead to a profound underestimation of diatom diversity in tidal flats. Round (1996) extracted epipsammic diatom assemblages from a riverbed by mixing, settling, and decanting specimens repeatedly. However, he reported that loss of epipsammic diatoms and contamination by diatoms from other habitats were unavoidable. In the present study, we used a sieve rather than mixing, settling, and decanting to extract the attached epipsammic diatoms selectively. The dead frustules would theoretically be washed out while sieving, because they are loosely attached or merely trapped among the sand grains, whilst living ones adhere firmly to sand grains by their mucilage. 
Thus, we attempted to extract living epipsammic diatoms through a sieving preparation method.

We aimed to achieve a clear picture of the living diatom flora in a sandy tidal flat. To achieve this, we combined multiple methods for evaluating diatom species composition with different characteristics. We applied three different preparation methods: conventional preparation of acid cleaned materials, the nuclear staining method using Hematoxylin solution (Gотон 1988), and a newly introduced sieving method for the same samples. The different species compositions obtained via these three methods were evaluated in terms of species richness, diversity, and composition based on statistical analyses and the ecological characteristics of the observed species. Finally, we will propose a synthesis of the three methods to identify the living diatom flora in a sandy tidal flat.

\section{Materials AND Methods}

Study site. Samples were collected from the Fujimae Tidal Flat at Nagoya Port in Aichi Prefecture, central Japan (136 50'15"E, $35^{\circ} 04^{\prime} 49^{\prime \prime N}$ ) (Fig. 1). The Fujimae Tidal Flat is located at the mouth of three rivers: the Shonai River, Shin River, and Nikko River. The tidal flat has a total area of $3.23 \mathrm{~km}^{2}$. The average monthly tidal range (based on tide observations for over 12 months) is approximately $2.6 \mathrm{~m}$ with sediments consisting of $20 \%$ silt and $80 \%$ fine sand (Shonai River OfFice 2006). Diurnal variation of salinity approximately ranges from 4 to 16 psu (YAGI et al. 1999). The Shonai River and Shin River feature some salt marshes consisting of patchy colonies of the reed, Phragmites australis. Because the Nikko River is a high-bedded river, it has a lock gate to prevent the backflow of seawater with stagnant backwater.

Sampling procedure. Sediment samples were collected during the exposure period at low tide in July 2014. Surface samples down to a $1.5 \mathrm{~cm}$ depth were collected using a tip cut syringe with a $2.7 \mathrm{~cm}$ diameter. We set a sampling area of 14,400 $\mathrm{m}^{2}$ and collected 25 samples from the area. Each sample was fixed with a $2 \%$-formaldehyde solution and preserved in a refrigerator.

Conventional acid-cleaning method. We made conventional permanent slides of cleaned diatoms, following the method of AKIBA \& SUTO (2013). Cells collected via this method should contain all diatoms, living or dead, in the sample. Fixed sample material was boiled in a $10 \%$-hydrogen peroxide $\left(\mathrm{H}_{2} \mathrm{O}_{2}\right)$ solution to remove organic matter, and then $1 \mathrm{~N}$ hydrochloric acid $(\mathrm{HCl})$ was added to remove calcareous materials. After washing with distilled water, a sodium pyrophosphate solution $\left(\mathrm{Na}_{4} \mathrm{P}_{2} \mathrm{O}_{7} \cdot 10 \mathrm{H}_{2} \mathrm{O}, 0.01 \mathrm{~N}\right)$ was added to remove clay particles that could hinder the preparation of permanent slides. The sample was again washed with distilled water to obtain cleaned frustules. The solution containing cleaned frustules was deposited onto the cover glass, dried on a hot plate at $60{ }^{\circ} \mathrm{C}$, and mounted using Pleurax (Mountmedia, Wako Pure Chemical Industries, Tokyo, Japan at approximately $200{ }^{\circ} \mathrm{C}$ ) to make a permanent slide.

Nuclear staining method to distinguish living diatoms from dead ones. This method allows the observation of the fine structure of the diatom frustules and the evaluation of the state of the cells by staining the nuclei and decolorizing the plastids (Gотон 1988). The fixed sample was stirred, and then the suspension was repeatedly centrifuged for five minutes at $1600 \mathrm{rpm}$ and rinsed to remove the formaldehyde. The diatom nuclei were then stained with filtrated Mayer's Hematoxylin solution (Wako Pure Chemical Industries, Tokyo, Japan) for 15 minutes at room temperature. After this treatment, the samples were washed three times with distilled water and centrifuged (1600 rpm for five minutes), and the liquid layer was discarded. The samples were then decolorized in ethanol for five minutes. After centrifuging (1600 rpm for five minutes), the solution was decanted twice, and the liquid was replaced with $96 \%$ ethanol. Each treated sample was placed onto a cover glass, then dried at the room temperature, and mounted using Pleurax at approximately $80{ }^{\circ} \mathrm{C}$ to make a permanent slide.

Sieving method for the extraction of epipsammic diatoms. This method selectively detects epipsammic diatoms attached to sand grains. The limit for particle size separating sand and silt is defined as $63 \mu \mathrm{m}$ in the Wentworth scale. Wet sediment sample was washed with distilled water using a sieve with a mesh aperture of $63 \mu \mathrm{m}$. Epipsammic diatoms firmly attached to sand grains remained in the sieve, whilst loosely attached or entangled dead diatoms were washed out along with silt and clay. The residue was dried in an oven at $60{ }^{\circ} \mathrm{C}$. It was then boiled with $10 \% \mathrm{H}_{2} \mathrm{O}_{2}$ solution for 20 minutes to decompose organic matter, and then $1 \mathrm{~N} \mathrm{HCl}$ was added to decompose calcareous matter. The sample was then washed with distilled water by settling and decanting three times, to remove remaining $\mathrm{HCl}$ and calcium ions. The permanent slides were made in the same way as in the conventional cleaning method.

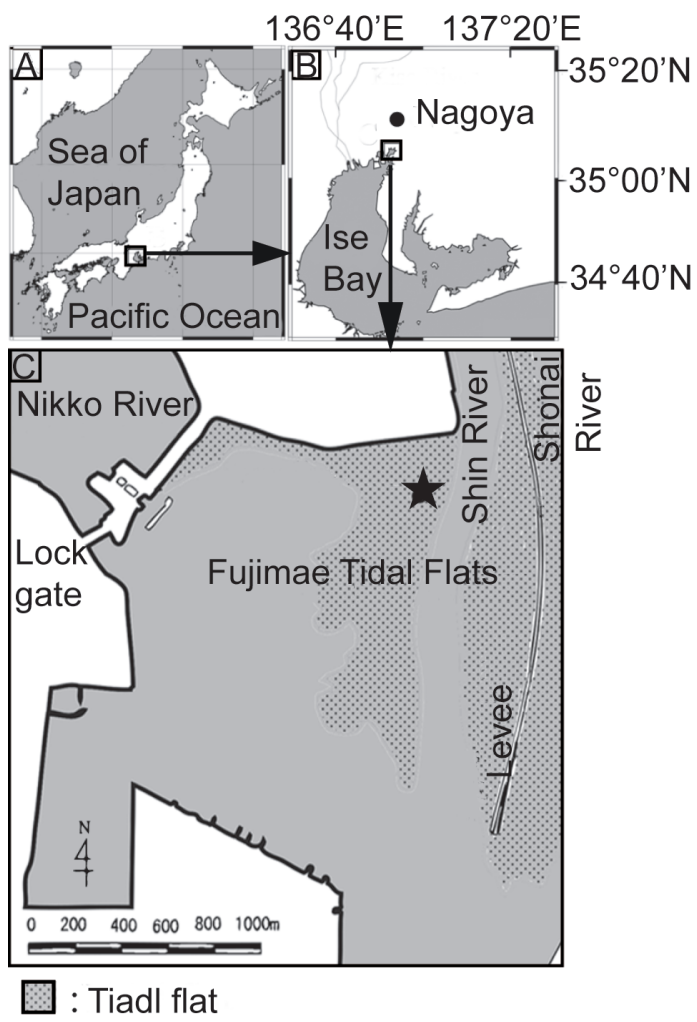

Fig. 1. Location of the Fujimae Tidal Flats. Dotted areas in Map C indicate intertidal areas. Sampling site is indicated by a symbol of star. (Modified from the map in SHONAI River OfFICE 2006) 
Species identification and counting. Living diatoms always retain intact frustules (i.e., a set of upper and lower valves, usually with girdle bands) in the stained samples while those that are dead or acid-cleaned ones are often separated into unilateral valves. Therefore, we counted 150 cells from each sample for the staining method and 300 valves for both acidcleaning and sieving methods, respectively. They are equivalent in the number of valves. We observed the slides with a light microscope (BX50, Olympus, Tokyo, Japan), with an objective lens of $\times 100$ (N. A. $=1.3$, oil immersion) and equipped with a digital camera (DP70, Olympus, Tokyo, Japan). As the micrographs of nucleus-stained specimens were sometimes not clear enough for precise identification, they were compared with the subjected acid cleaned valves to identify. Some of the cleaned diatoms were identified using a scanning electron microscope (SU6600, Hitachi, Tokyo, Japan).

Evaluation of the three methods through statistical analyses. We expected that the acid-cleaning method would extract all diatoms alive or dead, while the staining method would detect only living diatoms (excluding epipsammic diatoms), and that the sieving method would selectively detect the epipsammic diatoms. Therefore, the assessed species richness, diversity, and composition of a sample might different depending on the method used.

We tested the three methods for differences in their assessment of species richness and diversity. The Shannon-Wiener index $\left(H^{\prime}\right)$ was applied for diversity, which is calculated by following equations

$$
\mathrm{H}^{\prime}=-\mathrm{P}_{\mathrm{i}} \sum_{\mathrm{i}=1}^{\mathrm{s}} \log _{2} \mathrm{P}_{\mathrm{i}}, \quad\left(\mathrm{P}_{\mathrm{i}}=\frac{\mathrm{N}_{\mathrm{i}}}{\mathrm{N}}\right),
$$

where $s$ is the number of species, $N_{i}$ is the detected number of species $i$, and $N$ is the total counted number (OHGAKI 2008). We performed two statistical analyses to identify the differences; the Friedman test and the Wilcoxon signed rank test. Since the three methods were applied to the same sample and the number of samples was small (25 samples for each method) irrespective of the non-normality of the data, we conducted the Friedman test, which is applicable to non-parametric, paired multiple comparison tests (KURIHARA 2011). When significant

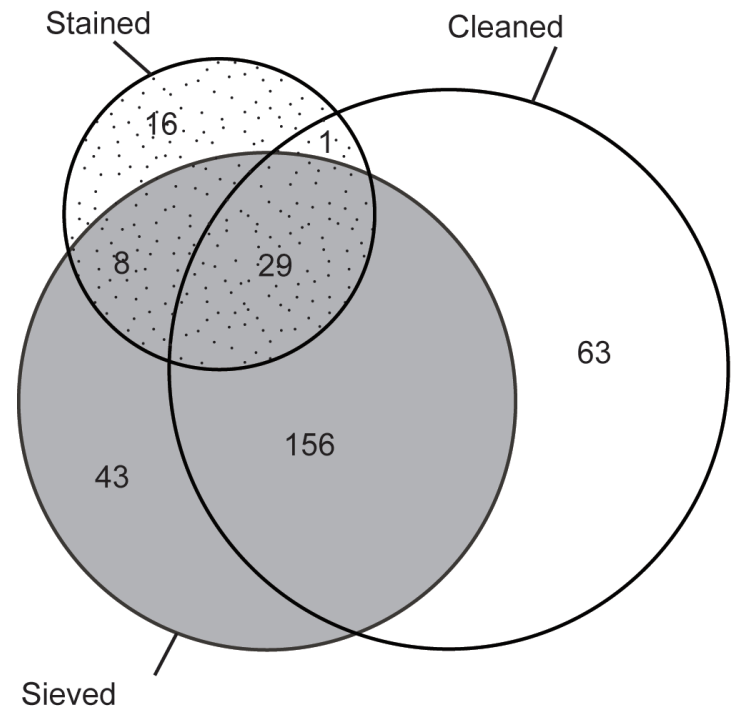

Fig. 2. Venn diagram showing the number of diatom taxa identified, including unidentified species, through three methods: a conventional cleaning method, a staining method, and a sieving method. differences were detected, post hoc test for Friedman tests were applied for comparison between two groups.

We compared relative frequencies of each abundant species between the three preparation methods using the Wilcoxon signed rank test (SHIMIzU 2004). In order to reduce the risk of type 1 error (null hypothesis is rejected even though it is actually true and should not be rejected), we adjusted the significance level by Bonferroni correction (SHAFFER 1995), thus the significance of $5 \%$ was divided by the number of groups (3 groups) and a significance of $1.7 \%$ was applied. We targeted taxa which were detected in more than 10 samples among the 75 samples observed. All statistical analyses in the present study were performed using R. 3.4.0 (R-project) and RStudio ver. 1.1.453.

Habitat salinity and life form of diatom species. We focused on criteria concerning habitat salinity: fresh, brackish (including fresh/brackish, brackish/marine, and fresh/brackish/marine), and marine, and diatom life form; planktonic, motile, and sessile. In tidal flats, motile (sometimes called "unattached" or "free-living") diatoms are usually epipelic. Sessile diatoms attach firmly to the substrata, and are also referred as prostrate, haptobenthic, epipsammic, epiphytic, and epilithic. Habitat salinity and life form information were found from the references (e.g. Carpelan 1978; Vos \& De Wolf 1993; VAN Dam et al. 1994; Chiba \& SaWAi 2014; Guiry, M.D. \& Guiry, G.M 2018; MiRANDA \& GUIRY 2018). When detailed descriptions for a species was lacking in the literature, we consulted information on organism's genus instead (Round et al. 1990).

\section{RESULTS}

Number of species detected by three methods. We detected 316 taxa using the three methods. The number of taxa detected by each of the methods are shown in Fig. 2. The staining method highlighted the nuclei in the diatom cells (Figs 3, 5, 7, 9, 13, 15). Among the three methods, the conventional acid cleaning method detected the largest number of taxa: 249 taxa belonging to 70 genera, followed by the sieving method: 236 taxa belonging to 64 genera, and the staining method: 54 taxa belonging to 24 genera. Although each method used the same material, there are multiple taxa detected solely by one of the preparation procedures: 63 taxa for the cleaning method, 16 taxa for the staining method, and 43 taxa for the sieving method.

The prediction states that the acid-cleaned samples should include all the taxa that are present in either stained or sieved ones, and there should be no taxa that are present in both stained and sieved ones. However, from the acid-cleaned samples we could not detect 24 taxa those were detected from stained ones, and 51 taxa from sieved ones. In addition, 37 taxa were common in both stained and sieved samples. The mean relative frequency of each species using the three methods, their habitat salinity, life form, and references are exhibited in Supplementary table (Table S1).

The dominant species identified by the three methods were as follows: for the acid-cleaning method, 
Staurophora dubitabilis (17.5\%, Figs 3, 4), Cyclotella meneghiniana (10.1\%, Figs 5, 6), and Aulacoseira granulata $(5.5 \%$, Figs 7,8$)$; for the sieving method, Hippodonta sp. 1 (5.9\%, Figs 9, 10), Staurophora dubitabilis (5.8\%), and Planothidium frequentissimum $(4.5 \%$, Figs 11, 12); and for the staining method, Pseudostaurosira trainorii (36.8\%, Figs 13, 14), Skeletonema costatum (19.1\%, Fig. 15), and Staurophora dubitabilis (10.8\%).
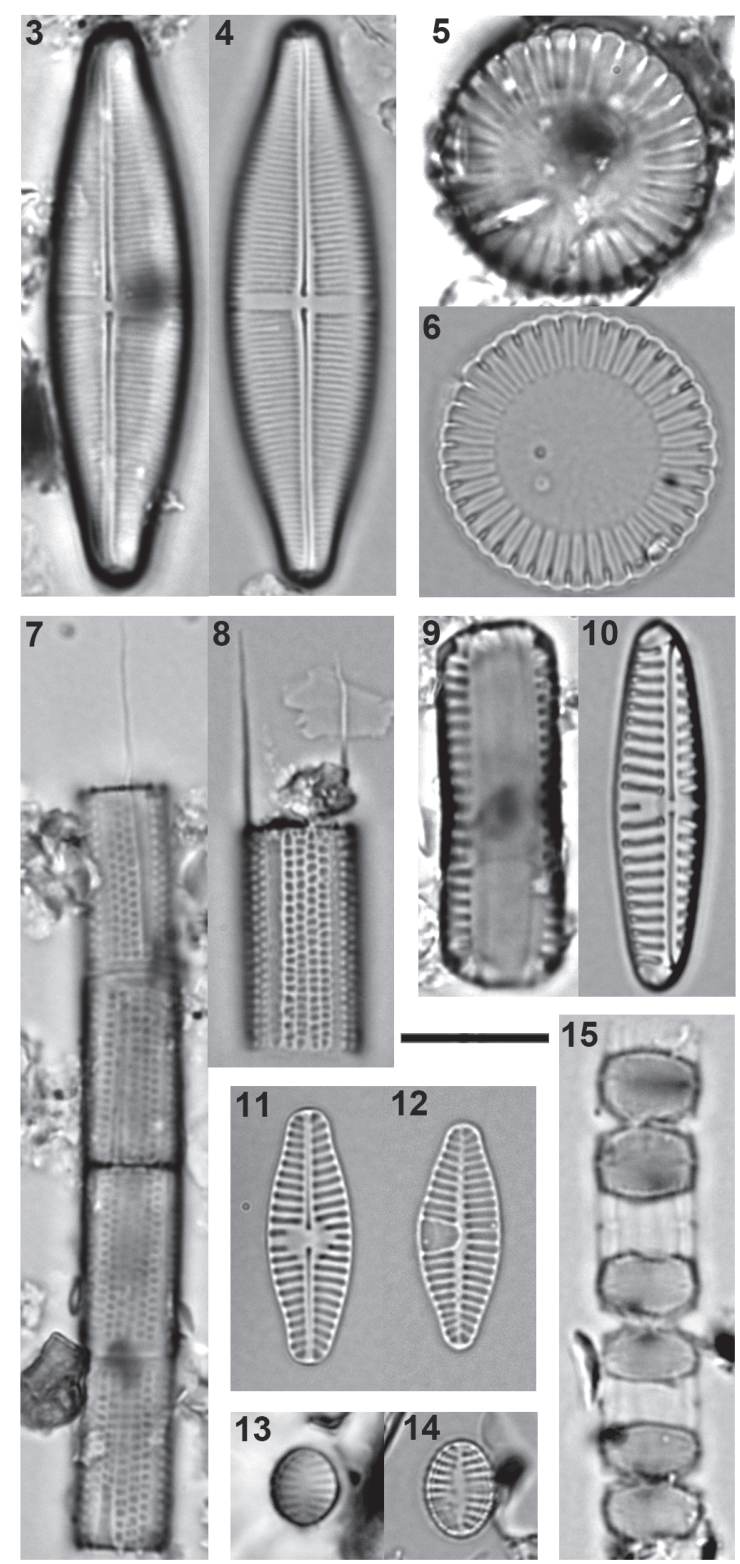

8
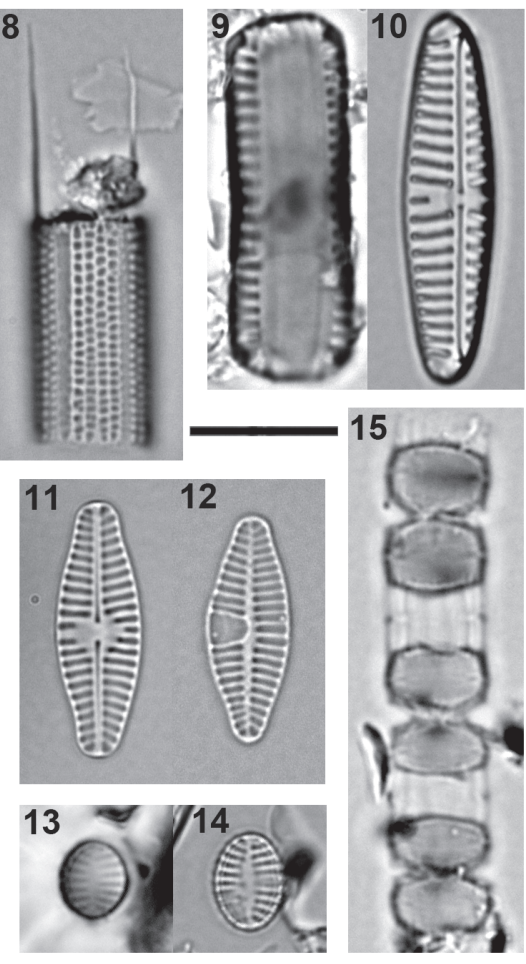

Figs 3-15. LM micrographs of the stained cells and cleaned cells of dominant species collected from the Fujimae Tidal Flat: (3) stained cell and (4) cleaned cell of Staurophora dubitabilis (Hustedt) Clavero \& Hernández-Mariné in Clavero (2009); (5) stained cell and (6) cleaned cell of Cyclotella meneghiniana Kützing; (7) stained cell and (8) cleaned cell of Aulacoseira granulata (Ehrenberg) Simonsen; (9) stained cell and (10) cleaned cell of Hippodonta sp.1.; (11) raphe valve and (12) rapheless valve of cleaned cells of Planothidium frequentissimum (Lange-Bertalot) Lange-Bertalot; (13) stained cell and (14) cleaned cell of Pseudostaurosira trainorii E.A. Morales; and (15) stained cells of Skeletonema costatum (Greville) Cleve. Scale bar is $10 \mu \mathrm{m}$.
Species diversity at 25 sites identified by each method. The differences in species richness and the ShannonWiener index of the 25 samples obtained using the three methods were compared as shown in Figs. 16 and 17. The Friedman test detected a significant difference in both species richness and Shannon-Wiener index between the three methods $(\mathrm{p}<0.001)$. The post hoc tests for species richness showed no significant difference between cleaned and sieved samples $(\mathrm{p}=0.086)$, but the staining method was significantly smaller than in both the sieved and acid-cleaned samples $(p<0.001)$. The Shannon-Wiener index indicated significant differences between each combination of the three groups (cleaned $<$ sieved, $\mathrm{p}=0.003$; sieved $>$ stained, $\mathrm{p}<0.001$; cleaned $>$ stained, $\mathrm{p}<0.001$ ).

The frequency of appearance of each species for the three methods. Using 75 subsamples $(25$ samples $\times 3$ methods), 127 taxa were detected in 10 or more subsamples. In total, a Wilcoxon signed rank test determined that significant differences existed in the detection 90 species between at least one combination of the three preparation methods with a $p$-value of less than $1.7 \%$. In terms of relative frequencies, 50 taxa exhibited the most abundant in the sieved samples, 42 in the acid-cleaned samples, and 5 in the stained samples.

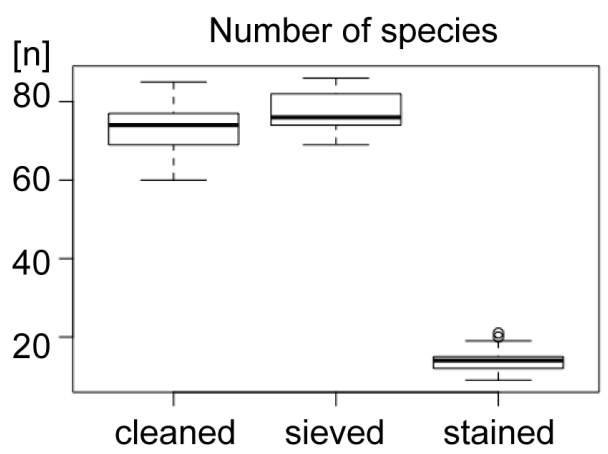

Fig. 16. Boxplot of the number of diatom species identified at 25 sites through three methods.

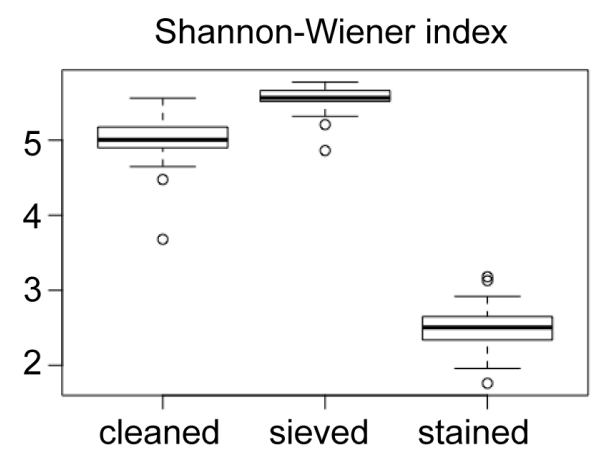

Fig. 17. Boxplot of the Shannon-Wiener index determined for 25 sites through three methods. 


\section{Discussion}

The differences in identified species diversity between the methods

The Friedman tests clearly showed differences between the three methods in terms of species richness and ShannonWiener's diversity $\left(\mathrm{H}^{\prime}\right)$, although the difference between acid-cleaned and sieved samples are not distinct. It was expected that species diversity in acid-cleaned samples would be higher than in the stained ones because most of the dead and/or epipsammic diatoms would be excluded in the latter. In addition, the acid-cleaning procedures separate the valves from the frustules and increase the probability that rare species were counted as single valves. This partly explains the higher species richness and diversity in the acid-cleaned and the sieved methods compared to the stained one, although it cannot be the sole reason for the marked differences. The small difference between acid-cleaned samples and sieved ones is notable, because the latter also should have excluded most of the dead and/or epipelic diatoms. This issue will be discussed below through a detailed comparison between the species compositions.

Diatom species extracted by the acid-cleaning method The freshwater diatoms which were present in the acid-cleaned samples but were much rarer or absent in both the stained and sieved samples, were presumed to be allochthonous. Among the 63 taxa which were found only in the acid cleaned samples, 34 were freshwater species belonging to genera such as Eunotia, Gomphonema, and Luticola (Fig. 2, Table S1). They were presumed to have been dead by the time of sampling, unless some of them were still living but not detected because of their rarity. Among the 42 species which were significantly more abundant in terms of relative frequency in the acid cleaned samples than in the others, 29 taxa were freshwater diatoms (e.g. Amphora copulata, Diadesmis confervacea, Encyonema simile, E. ventricosum, Eunotia metamonodon, E. sedina, Gomphonema contraturris, G. inaequilongum, G. sp.3, Pinnularia oriunda, P. parvulissima, $P$. schoenfelderi, and $P$. sp.2; Table S1). Because most of them were absent or very rare in the stained and sieved samples, they were also considered to be from the river.

Some previous studies have reported that allochthonous frustules brought by tidal currents and river inflow becomes significant contaminants in coastal wetlands (e.g. KosUgi 1986b; Vos \& DE Wolf 1993; SAWAi 2001). Gотон (1988) also stated that "conventional cleaning method leads to misunderstanding of the diatom assemblage when the sample contains many dead or allochthonous cells."

However, many brackish motile diatoms, which were the most abundant in the acid-cleaned sample, were also rare in the stained samples. They correspond to Bacillaria paxillifera var. tumidula, B. urve-millerae, Entomoneis japonica, Hantzschia amphioxys, Navicula degitoradiata, Parlibellus cruciculoides, Petroneis marina and Tryblionella apiculata. Except Staurophora dubitabilis (10.8\%), these brackish motile diatoms were rare in the stained samples in terms of relative frequency $(0 \%-0.7 \%)$, irrespective of their nature as a potential component of tidal flat diatoms. We hypothesize that while they used to be live in the tidal flat, they were already dead by the time of sampling.

\section{Diatom species extracted by the sieving method}

Diatoms identified through the sieving method were typically of the sessile type (Table S1). They included many monoraphid species belonging to Achnanthidium, Cocconeis, Planothidium, and other Achnanthes sensu lato, which are monoraphid and strongly attach to substrata through secreted mucilage on their raphe valves (RouND et al. 1990). Many species were not found or were very rare in the stained samples. For instance, Achnanthidium exiguum, A. subhudsonis, Cocconeis lineata, Planothidium frequentissimum and $P$. rostratum were all found to have $0.0 \%$ mean relative frequencies in the stained samples, while they were all abundant in the sieved samples $(>$ $3 \%$ ). Small and prostrate Sellaphora nigri were also showed a similar tendency $(0.0 \%$ in stained samples vs. $4.4 \%$ in sieved ones). These results suggest that the sieving method can scrape the epipsammic diatoms selectively and supplements the staining method, in which epipsammic diatoms are mostly neglected.

Many freshwater diatoms were abundant in the sieved samples irrespective of the brackish nature of the Fujimae Tidal Flat (4-16 psu; YAGI et al. 1999). For instance, Achnanthidium convergens (0.8\%), A. subhudsonis (3.1\%), Karayevia clevei (0.2\%), Nitzschia fonticola (2.6\%), and Planothidium frequentissimum var. magnum $(0.8 \%)$ are usually referred to as freshwater taxa in the past literature. They may be resistant to brackish environments, and travel via rivers attached to sand grains. These contaminations of freshwater species might partly explain the relatively higher species richness in the sieved samples.

Unexpectedly, some planktonic diatoms such as Cyclotella atoms, C. cryptica and C. meduanae were significantly more abundant in the sieved samples than in the acid-cleaned ones. These diatoms can be trapped within the biofilm on the sand grains and sometimes attach to the substrata through their own mucilage, which is likely why they occurred in the sieved samples. Their relative abundances, however, should be higher in the acid-cleaned samples than in the sieved ones. A possible explanation of why the reverse occurred is that the procedure to remove clay particles in the acid-cleaning method washed away these small diatoms, while the sieving method did not employ this process.

\section{Diatom species extracted by the staining method}

The staining method showed an advantage in that it could not only selectively detect living diatoms but also fragile and/or small ones. Some diatom taxa with fragile 
frustules (e.g. Chaetoceros minimus, Cylindrotheca gracilis, Entomoneis aequabilis, E. paludosa, Skeletonema potamos) and/or small-sized cells (e.g. Cyclotella atomus, C. cryptica, Discostella wolterecki) were detected only by the staining method. Previous studies point out that the acid solution and the decanting procedure of the acid-cleaning method sometimes break the cells (e.g. Beyens \& Denys 1982; Hirose et al. 2013; CHiBA 2014). We also suspect that small-sized cells remained suspended in the supernatant water during the cleaning due to the use of a dispersing agent and were therefore washed out. Our results show that the staining method can detect diatoms with fragile frustules and small-sized cells more effectively than the conventional acid-cleaning method.

Five taxa were significantly more abundant in samples evaluated using the staining method than in either of the other two methods. These species were autochthonous with high abundance (e.g., 36.8\% for Pseudostaurosira trainorii, 19.1\% for Skeletonema costatum, and $5.7 \%$ for Navicula arenaria var. rostellata). Among them, P. trainorii is considered to be a freshwater species. However, this might be a misidentification of Staurosira sopotensis (WITKOWSKI 1994), and it is also possible that they belong to the same species.

\section{Evaluation of the three methods}

The conventional acid-cleaning method alone should not be used for floristic studies of the tidal flat diatoms, although it is necessary to identify these diatoms precisely. In this study, the diatom flora identified through the acid-cleaning method contained many species to be allochthonous, belonging to freshwater genera such as Eunotia, Gomphonema, and Luticola. These subsamples also contained species which were possibly autochthonous, but apparently have died at the sampling time, such as Hantzschia amphioxys, Bacillaria paxillifera var. tumidula, and Navicula digitoradiata. In addition, this method cannot detect many diatoms with fragile and/or small cells (see above).

The staining method selectively extracts living cells, especially fragile and small species such as Chaetoceros minimus, Cylindrotheca gracilis, Entomoneis aequabilis, Cyclotella atomus, C. cryptica, and Discostella wolterecki, which are frequently overlooked by the acid-cleaning method. Conversely, this method overlooked most of the sessile or epipsammic diatoms which were attached to the sand grains, and thus caused an underestimation of the species diversity.

The diatoms detected by the sieving method were characterized by the sessile type, such as Achnanthidium, Cocconeis, Planothidium, and Sellaphora, which the staining method could hardly detect. This method also has an advantage over the conventional acid-cleaning method in that the procedure to remove clay particles can be omitted, and small-sized diatoms can thus be detected efficiently.

The combination of the three methods employed in this study can be used to more precisely identify the living diatom flora of tidal flats than the approaches used in previous studies.

\section{Three advantages of the combined method}

In this section, we discuss three advantages that our combined method to evaluate diatom flora has over methods used in the past studies.

The first advantage of our combined method is the elimination of allochthonous diatoms. As discussed above, the acid-cleaning method cannot eliminate allochthonous diatoms. Previous studies on tidal-flat diatom flora have often documented many freshwater diatoms irrespective of the high salinity. For instance, salinity ranges from 8-35 psu in the Yaquina Estuary (RIZNYK 1973) and approximately 25-30 psu in the Ariake Sea (OHTSUKA 2005; PARK et al. 2012). As both areas feature much higher salinity than that of the Fujimae Tidal Flat (4-16 psu), most of the freshwater diatoms identified there are presumed to be allochthonous. Other methods such as the cover-glass technique (OPPENHEIM 1991) and lens-tissue one (COLIJN \& DiJKEMA 1981) can select living diatoms, but they may also exclude many planktonic or sessile diatoms with low motility.

The second advantage is the detection of fragile and/or small diatoms. The staining method in the present study revealed a novel and unexpected aspect of tidal-flat diatom flora: many diatoms with fragile frustules lived there. We found fragile diatoms such as Chaetoceros minimus, Cylindrotheca gracilis, Entomoneis aequabilis, E. paludosa, and Skeletonema potamos from the surface of the sand. Such diatoms have been scarcely detected in most previous studies (RIZNYK 1973; ColiJn \& DiJKema 1981; Oppenheim 1991; OHtSUKa 2005; PARK et al. 2012), with the exception of SABBE (1993), which detected the fragile diatom Nitzschia closterium as a major component. It is probable that these fragile diatoms are destroyed during the cleaning process. Small diatoms could be washed out if a suspending agent is used to remove clay particles, as the present study demonstrated. In principal, the cover-glass technique (OPPENHEIM 1991) or the lens-tissue technique (CoLIJN \& DiJKema 1981) could identify such diatoms, but in reality, such diatoms are rarely detected because of their non-motile nature or weak adhesive power.

The third advantage of the combined method is the effective detection of sessile diatoms that attach to sand grains. Because sessile diatoms usually move more slowly than motile ones (HARPER 1977), both the cover-glass technique (OPPENHEIM 1991) and the lenstissue technique (CoLIJN \& DiJKema 1981) are assumed to collect them less effectively than our sieving method. This assumption, however, might not apply to diatoms such as Planothidium and Halamphora, because these diatoms were also reported by CoLIJN \& DiJKema (1981) and OPPENHEIM (1991). Although the conventional acidcleaning method can also detect these sessile diatoms, it cannot separate the allochthonous ones from those 
living on the sand grains in the tidal flats.

We are convinced that we can assess the living diatom community on a tidal flat more thoroughly than previous diatom studies through the combination of these three preparation methods. Such combined methods are necessary to precisely describe diatom flora, especially those of depositional environments where dead diatom frustules are abundant and multiple microhabitats are present even within a sample.

\section{ACKNOWLEDGEMENTS}

Special thanks to Professor Toshikazu Gotoh (Kinki University) for his useful advice on the nuclei staining method, and the members of the Tansaibou no kai, Lake Biwa Museum for providing critical advice and comments on diatom identification. We also wish to thank Dr. Seiji Hayashi (Nagoya University) for the use of the scanning electron microscope and Professor Kenichiro Sugitani (Nagoya University) for assistance in our sampling collection and his constructive comments. We appreciate the members of the Save Fujimae Association, who were always helpful in our sampling, for the use of their facilities. Without their contributions to saving the area, the Fujimae Tidal Flat would not exist.

\section{REFERENCES}

AkIBA, F. \& Suto, I. (2013): Sample treatment and preparation. - In: Oda, M. \& SATO, T. (eds): "Bikaseki Kenkyu Manual" Manual for Microfossils Research. - pp. 37-43, Asakura Publishing, Tokyo.

Beyens, L. \& Denys, L. (1982): Problems in diatom analysis of deposits: allochthonous valves and fragmentation. - Geologie en Mijnbouw 61(2): 159-162.

CARPELAN, L.H. (1978): Evolutionary euryhalinity of diatoms in changing environments. - Nova Hedwigia 29: 489-526.

ChiBA, T. (2014): Taphonomy of diatoms and problems of paleoenvironmental reconstruction in coastal areas using diatom assemblages. - Diatom 30: 86-103.

Chiba, T.; Endo, K. \& Masubuchi, K. (2011): Size distribution of diatom frustules and sedimentary process of dead diatoms in a tidal zone. - The Quaternary Research 50(6): 279-293.

ChIBA, T. \& SAWAI, Y. (2014): Reexamination and updating of diatom species for paleoenvironmental reconstructions. - Diatom 30: 17-30.

Colijn, F. \& Dijkema, K.S. (1981): Species composition of benthic diatoms and distribution of chlorophyll $a$ on an intertidal flat in the Dutch Wadden Sea. - Marine Ecology Progress Series vol. 4: 9-21.

Gотон, T. (1988): Analysis of diatom community by the cell nucleus staining method. -Diatom 4: 67-72.

GuirY, M.D. \& GuirY, G.M. (2018): AlgaeBase. World-wide electronic publication, National University of Ireland, Galway. -http://www.algaebase.org; (Accessed on 05 June 2018).

Harper, M.A. (1977): Movement. - In: Werner, D. (ed): The Biology of Diatoms. - pp. 224-249, Blackwell Scientific Publications, Oxford.

Hirose, K.; Yoshioka, K.; Irizuki, T.; IwaI, M. \& Gotoh T. (2013): A study on the utility of ultrasonic treatment for preparing fossil diatom slides. - The Quaternary Research 52: 213-224.

Kosugi, M. (1985): Discrimination of living or dead cells of diatoms based on the stained images - its method and significance. - The Quaternary Research 24: 139-147.

Kosugi, M. (1986a): Transportation and sedimentation patterns on dead diatoms in a tidal flat area - a case study in the lower reach of the Obitsu river. - Geographical Review of Japan 59: 37-50.

Kosugi, M. (1986b): Some fundamental problems on Paleoecology of Diatoms. - Diatom 2: 169-174.

Kosugi, M. (1988): Classification of living diatom assemblages as the indicator of environments, and its application to reconstruction of Paleoenvironments. - The Quaternary Research 27: 1-20.

Kurihara, S. (2011): The basis of a statistics - test to multivariate analysis and experimental design. -319 pp., Ohmsha, Tokyo.

Mayama, S. \& Kobayasi, H. (1982): Diatoms from the Aonogawa River. - Bulletin of Tokyo Gakugei University 34: $77-107$.

MirandA, S.V. \& GuIRY, G.M. (2018): AlgaeBase. World-wide electronic publication, National University of Ireland, Galway. -http://www.algaebase.org; (Accessed on 05 June 2018).

OHGAKI, S. (2008): Diversity and similarity, taxonomical new indexes. Argonauta 15:10-22.

OHTSUKA, T. (2005): Epipelic diatoms blooming in Isahaya Tidal Flat in the Ariake Sea, Japan, before the drainage following the Isahaya-Bay reclamation project. - Phycological Research 53: 138-148.

Oppenheim, D.R. (1991): Seasonal changes in epipelic diatoms along an intertidal shore, Berrow Flats, Somerset. Journal of the Marine Biological Association of United Kingdom 71: 579-596.

PARK, L.; Khim, J.S.; OhtSUKa, T.; Araki, H.; WitKowsKi, A. \& KoH, C.-H. (2012): Diatom assemblages on Nanaura mudflat, Ariake Sea, Japan: with reference to the biogeography of marine benthic diatoms in Northeast Asia. - Botanical Studies 53: 105-124.

RIZNYK, R.Z. (1973): Interstitial diatoms from two tidal flats in Yaquina Estuary, Oregon, USA. - Botanica Marina 16: $113-138$.

Round, F.E. (1996): Epipsammic diatoms - communities of British rivers. - Diatom Research 11: 363-372.

Round, F.E.; Crawford, R.M. \& Mann, D.G. (1990): The diatoms Biology and morphology of the genera. -747 pp., Cambridge University Press, Cambridge.

SABBE, K. (1993): Short-term fluctuations in benthic diatom numbers on an intertidal sandflat in the Westerschelde estuary (Zeeland, The Netherlands). - Hydrobiologia 269/270: 275-284.

SAWAI, Y. (2001): Distribution of living and dead diatoms in tidal wetlands of northern Japan: relations to taphonomy. - Palaeogeography, Palaeoclimatology, Palaeoecology 173: 125-141.

SHAFFER, J.P. (1995): Multiple hypothesis testing. - Annual Review of Psychology 46:561-584.

Shimizu, N. (2004): Statistics for writing thesis. - 150 pp., OMS, Tokyo.

Shonai River OfFice (2006): Investigation report of estuarine tidal flat of Shonai River and Shin River. - 326 pp., Shonai River Office, Chubu Regional Bureau, Ministry of Land, Infrastructure, Transport \& Tourism, Nagoya.

SMith, D.J. \& UNDERwood, G.J.C. (1998): Exopolymer production by intertidal epipelic diatoms. - Limnology and Oceanography 43:1578-1591.

Underwood, G.J.C. \& Kromkamp, J. (1999): Primary production by phytoplankton and microphytobenthos in 
estuaries. - Advances in Ecological Research 2: 93-153.

Van Dam, H.; Mertens, A. \& Sinkeldam, J. (1994): A coded checklist and ecological indicator values of freshwater diatoms from the Netherlands. - Netherlands Journal of Aquatic Ecology 28: 117-133.

Vos, P.C. \& De Wolf, H. (1993): Diatoms as a tool for reconstructing sedimentary environments in coastal wetlands; methodological aspects. - Hydrobiologia 269/270: 285-296.

Witкowski, A. (1994): Recent and fossil diatom flora of the Gulf of Gdańsk, Southern Baltic Sea. -In: Bibliotheca Diatomologica 28. - 313 pp., J. Cramer, Berlin, Stuttgart.

Yagi, A.; Suzuki, Y.; SaKazaki, K. \& Neriki, K. (1999): The presumption of aqueous exchange by chlorine ion concentration fluctuations in sea and interstitial waters at the time of the low and high tides in Fujimae Tidal Flat. - Journal of Nagoya Women's University 45: $183-188$.

Supplementary material

The following supplementary material is available for this article: Supplementary Table S1.

This material is available as part of the online article (http:// fottea.czechphycology.cz/contents)

(C) Czech Phycological Society (2020)

Received March 29, 2019

Accepted October 15, 2019 